\title{
Whole Organism Analysis
}

National Cancer Institute

\section{Source}

National Cancer Institute. Whole Organism Analysis. NCI Thesaurus. Code C19125.

Histological techniques in which thin sections through the entire animal are used. 